CASE Xvi.-The following is a case in which the drill might, no doubt, have been successfully employed, but in which the nature of the exostosis admitted the use of a readier means of extirpation. The patient was sent up from the country to the George Bird Ward, St. Mary's Hospital. I found that he had for years, on and off, suffered from discharge from the left ear, and that he had latterly complained of great pain on the left side of the head. The meatus, as examination with a probe revealed, was completely occupied by a large and apparently fixed spongy osteoma. Directly the patient was well under the influence of chloroform, I seized, and without much difficulty removed, with strong forceps, a growth measuring three-quarters of an inch in length and one-third of an inch in thickness.

The above cases I have recorded as showing the possible importance, nay, in some cases, the urgent necessity of operating for the removal of aural exostosis. But, as this may be no trifling matter, it is perhaps advisable to point out the class of cases in which (1) an operation is not requisite, and (2) is altogether unjustifiable. I have been sent numerous cases of multiple exostoses, in many of which I have bcen able to give the assurance that no operation is or probably will be needed, although deafness may for a time have been almost absolute. These bony excrescences, in many an instance, occur opposite to one another, and, as they grow, become wedged together, so that increase at the extremities is arrested, and a triangular central space is left. This channel, when very small, as not unfrequently, may afford a sufficiently free passage for sound, but readily becomes blocked by cerumen or even water, with the result of causing complete deafness. Careful cleansing of the meatus must then be resorted to, and the patient should be warned never by any means to allow water to enter the ear. Practice of this precaution, and occasional repetition of the cleansing, may be all that is required for the continued preservation of the hearing.

I was, some time ago, consulted by two brothers, the one a medical man, and the other a celebrated actor, each the subject of bilateral multiple exostoses, originating in oft-repeated sea-bathing. To them, as to any others occupied in a more or less public capacity, impairment of hearing would have been a matter of most serious import. I was able to assure them of the high probability of what they have for two or three years since enjoyed, continuance of perfect audition without recourse to operation. This, however, could scarcely have been expected had each meatus contained what are sometimes to be met wich, namely, four or five exostoses growing close together or behind one another. Such a condition obtained in the case of a distinguished lawyer, under my care for some few years. As he came to see me every two or three months, I was for long enabled to keep the meatus clear ; but latterly its calibre became so much reduced that, as deafness would have been incompatible with the discharge of his official functions, an operation must soon have been imperative had not his death occurred from bronchitis.

The cases in which operation is unjustifiable are those in which it would be dangerous, because of the growth being not only of extreme density, but situated at a great depth within the meatus. Cases of deeply seated soft exostoses (spongy osteomata) may, on the other hand, be treated instrumentally without risk, as in the instances of removal by forceps above recorded. The confounding of these with the harder growths has doubtless led to the accounts, occasionally to be met with, of the ready removal of ivory exostoses after a few minutes' drilling. As we have seen, the drill may be quite unnecessary for the softer class of excrescences, whereas experience proves that it alone, used for a considerable length of time, can be of any avail for the penetration of the harder growths.

These cases only go to strengthen conclusions long since arrived at by me:-(1) that aural exostoses must not be considered as at all necessarily the outcome of gout, rheumatism, or syphilis ; $(2)$ that their origin can, with strong probability, be attributed, in many, if not in all cases, to some preceding local irritation; (3) that they can be safely and most effectually treated by drilling, when a suitable guard is employed to protect adjacent structures; (4) that their speedy removal is indicated wherever they hinder the elimination of secretions and discharges from the auditory canal, cause pain by pressure, or impair or prevent audition.

Medical Magistrate.-Dr. W. R. Haydon has been placed on the Commission of the Peace for the Borough of Tiverton.

Wigan Medical Societr. - The following office-bearers have been elected for 1886. President: William Berry, Esq., J.P. Vice-President: J. B. Stuart, Esq., F.R.C.S.Ed. Honorary Secretary and Treasurer: R. P. White, M.B.Ed. Committee: J. White, Esq., J.P., W. C. Burnish, Esq., N. Hannah, Esq.

\section{A REPORT OF THE CAUSES OF BLINDNESS}

IN 111 INMATES OF, OR WORKERS AT, THE SHEEFIELD INSTITUTION FOR THE BLIND, WITH REMAIIKS.

\section{BY SIMEON SNELL, M.R.C.S.Eng.,} Ophthalmic Surgeon to the Sheffield General Infirmary, and to the Institution
for the Blind.

THE present report is based on an examination of the cinildren or young people, inmates of the Sheffield Blind School. Generally speaking, shortly after admission, each 'scholar has been examined by me, and thus, with one or two exceptions, each case has passed under my direct observation. The medical certificates with which each applicant for admission has to be provided, though answering well their immediate purpose, are, generally speaking, too vague to render much aid to scientific inquiry. Where it has been possible to clear up doubtful points by communicating with the children's parents or friends, it has been done; but, in some instances, among inmates coming long distances, from the North or South of England, this has been impossible. Care has, however, been taken to render the report as accurate as circumstances permitted. The numbers have been increased by an examination of the workers at the Workshops for the Blind, a part of the same institution.

Since the Blind School was opened, I have records of 76 cases; from this number, 3 are excluded from consideration, as not having been seen by me, or for other reasons, thus reducing the total to 73 . Of this number, 41 are males and 32 females.

At the Workshops, a total of 46 are employed, and all have been examined. Eight had, however, been already noted whilst previously attending the blind school, and the number is consequently reduced to 38 . Nine are females, and 29 males. The eight excluded were also males. The scholars, with one or two exceptions, are all under 15 years of age, and it is required that each should be of good health, and free from fits and mental or other afflictions, that would interfere with educational work, prior to industrial training. At the workshops, competency to learn and to perform the work undertaken would appear to be the only requirements for admission.

The series of observations recorded as to the causes of blindness in any given number of persons so afflicted are not many, and fewer are are those in which each individual case has been examined by the writer. I trust therefore that the present report, even with the limited number treated of, may be of some interest and value. I will proceed to separate into groups the various cases.

Ophthalmia Neonatorum. - Among the inmates of the Blind School, in no fewer than 27 , blindness can with tolerable certainty be assigned to this disease as a cause, and in one in all probability so; making a total of 28 , or 38.3 per cent. At the Workshops, the number is 10 , or 26.3 per cent. The difference in percentage between the blind of the two establishments appears just what would be anticipated. For, in the Blind School, all are young people, with very few exceptions under 15 years of age; whilst at the Workshops are adults of all ages, amongst whom, increased age, the causes of blindness from occupation or otherwise, have come into play, and necessarily have reduced the percentage. The number, out of the total of 111 at the two establishments, afflicted from this disease, is 38 , or 34.2 per cent.

A point which may be mentioned in passing, is the greater number of males blind from ophthalmia neonatorum than females. In the Blind School, the numbers are 17 males, 11 females; at the Workshops, 7 males, and 3 females. The greater number of males among those generally under consideration may, of course, be held to account for this difference; but does it do so altogether? Among the last 78 cases of this disease registered at the Sheffield General Infirmary, it would seem that 42 were males and 36 females, again a difference in favour of the male sex.

Blennorrhea in Adults or Subsequently to Infancy. - Threo cases at the Workshops, or 7.9 per cent., would appear to come under this head, two males and one female. A female, aged now 31, suffered from the disease at 13 , and has undergone operations (iridectomies?) in both eyes without benefit. A male, aged 48, suffered from ophthalmia in the East Indies as a soldier; now there is cornealstaphyloma and. general symblepharon; the right eye can see fingers. The other man, aged 36 , states that he lost his sight from contagious ophthalmia at 8 years of age; many other children suffered from the same disease at the time. The appearances of the eyes do not altogether bear this out. The case is one of interest. In February, 1877, he was under my care in the Infirmary. The cornea and the media were sufficiently. 
clear to enable a good view of the fundus to be obtained; a whitish yellow-looking appearance was observed even without tho ophthalmo. scope, but particularly with its aid. No vessels were traced over it, but its surface was irregular. The diagnosis suggested, of ossification of the choroid, was rendered more likely by palpation of the globe. Towards its posterior part, it felt quite hard and solid when touched with the fingers. The eyeball was at times irritable and painful, and it was therefore enucleated. On the interior of the eye being examined, it was found occupied by a large stout shell of bony deposit, thicker posteriorly, where was an aperture corresponding to theoptic nerve entrance of the free, and thinner at its anterior edge. It reached to some little distance behind the ciliary processes. The condition of the left eye on June, 1885, was as follows. There was a large leucoma, which, however, left a part of the pupil free ; there were myopia and large crescent; he had large pigmentary irregularities in the fundus (bony deposit?), but view was difficult.

Osseous deposit in an eye is frequently met with, but a case in which, during life, the media have remained clear, and for the condition to be diagnosed, is rare. Mention may be made of a case recorded by Professor Laqueur, of Strasburg, in Knapp's Archives of Ophthalmology for 1878 (vol. vi). A diagnosis of osseous deposit was made by the ophthalmoscope and by palpation, but enucleation was not resorted to.

In the Blind School two cases, where the eye was lost in early life, seem to come under this class. Both are males. One lost his sight at sixteen months, "cutting his corner teeth," the other at eight months and a half.

Sympatictic Ophthalmitis. - At the Blind School, there are six whose blindness may be assigned to this disease, or 8.2 per cent. The ages at which the exciting eyes were injured were 12, 7, 14, 4, with a sub. sequent injury at 8 (probably the really exciting hurt), 11,14 . The injuries were caused in the following ways : by a knitting needle, in one case ; blow from a stone, in one; hit with a stick, in two; a piece of pot, in one; in one, also, after typhoid fever, in which the cornea was destroyed (hypopyon ulcer), an iridectomy was attempted, and, failing to remove this iris satisfactorily, the ulcerated cornea was incised. In all the cases, the exciting eye was enucleated.

The time when the disease was set up in the sympathising eye is very uncertain, and should be stated in this way. In one case, the exciting eye was removed six months after the injury, and the other organ had been affected for some time, though, five months afterwards, he could still see to read with it; another (hypopyon ulcer), about two months ; in another, up to eleven months after injury, the other eye remained good ; in the others, no time is assigned, or very uncertainly.

In the Workshops, there are four cases of sympathetic ophthalmitis, or 10.5 per cent. The ages at which the accident to the exciting eye occurred were $22,22,21,16$; and the injury was occasioned by bursting of a ginger-beer bottle; the point of a scissors; a piece of steel penetrating the eye; a knife-blade projecting from machinery. In two only of these cases were the globes enucleated. The length of periods elapsing after injury, before the sympathising eye became affected, is thus stated. One commenced within the first two months, but sight was not entirely lost for two years; another began to fail a month after; and the other two at three weeks and six weeks.

There are 5 males and 1 female at the Blind School; and, at the Workshops, 3 males and 1 female. Of the whole number, 6 are right eyes and 4 left. Of the adults (4), in only half of the cases was the injury associated with their employment. Taken together, the early age at which all were attacked appears to favour the opinion that sympathetic ophthalmitis is more likely to occur in injuries anong the young.

I may mention that one inmate of the Blind School, in whom the acuteness of the attack had long passed, was admitted into the Infirmary under my care, and, after two operations, sufficient iris was removed to give him a useful pupil. There was occlusion of the pupil, and the lens appeared to have undergone absorption. He was, with a glass, enabled to read Jäger 2, and soon left the school to learn to earn his livelihood as a sighted worker.

In all, there were 10 cases of sympathetic ophthalmitis, out of a total of 111 , or 9 per cent.

Accidents, simultaneous to both eyes, and resulting in blindness, afford three instances at the Workshops, or $7.8 \mathrm{per}$ cent. They are all males. 1. Now aged 42 ; accident at age of 34 ; was blasting stone. 2. Aged $64 ;$ accident occurred twenty-five years ago, whilst blasting stone; a piece of stone stuck in the right eye ; the left retained a glimmer of sight for some time. 3. Aged 62 ; accident twenty-seven years since; whilst sinking a coal-shaft and blasting, powder struck his face; he "never saw again ;" powder-marks on his face. In each case, the corneæ in both eyes were completely de- stroyed; and one eyeball in the first case, and both in the third, were adherent to the upper eyelids.

Lime entering the eye appears to be the cause of blindness in one case at the Workshops. The man is now aged 54. At 3 or 4 years of age, he got lime in his eyes, and sight gradually went; he could continue as a labourer until 19. There are now xerosis of the cornea and conjunctiva, general symblepharon, and ingrowing eyelashes, for which he has un. dergone operation; the use of vaseline has enabled him to find his way about.

Small-pox is answerable for blindness in three cases at the Blind School, or 4.1 per cent. One case was not vaccinated, and had the disease when eighteen months old. Another, much pitted, had smallpox at three weeks, and is said to have been vaccinated after having the disease. The third case was only vaccinated in infancy, and has four fair marks, and was 16 years old when she suffered from smallpox. Two were males, and one a female.

At the Workshops, two assign their blindness to this disease, or 5.3 per cent. One had small-pox at 10 years of age; she is uncertain as to vaccination, but no marks are to be found; she is much pitted. The second case was not vaccinated. There was one female and one male. As to this last case, it should be mentioned that it was the left eye that was lost completely by the attack of small-pox. The right $\in$ ye was, he says, unaffected by small-pox, but my recollection is that, when he came to the Infirmary some time since, there was a small leucoma (adherens ?). On April 3rd, 1882, he was iridectomised for acute glaucoma; sight was nearly gone, a little vitreous humour escaped (he was a most unruly patient, and declined an anæs. thetic); ultimately, the globe shrank.

Altogether, the total number of cases blind from small-pox is 5 out of the 111 , or 4.5 per cent.

Scarlet fever occasioned one case of blindness at the School, or 1.3 per cent. It was a male, and occurred at 9 years of age. At the Workshops, there was one case, also, and it happened to a female, again, at the age of 9 . The percentage is 2.6 , or, of the total of 2 in 111 cases, 1.9 per cent.

Measles at the age of 11 months rendered one female at the School blind, or 1.3 per cent. There is no case at the Workshops.

Fever, probably typhoid, is assigned as the cause of blindness at the School, in a female, at 15 years of age, or 1.3 per cent. There is no case at the Workshops.

Cases of Congenital Blindness : Cataract. -At the Blind School there are five inmates whose blindness is traceable to this cause, or 6.8 per cent. All have undergone operations in both eyes, but in all the cases the operation would appear to have been delayed until late. In two the age is known fairly well, and was about eight years; another seems to have been near 10 years of age. Three have been operative successes, and they possess faint vision for large objects; 1 appears capable of improvement; 4 are males and 1 a female.

At the School also there are 7 , or 9.5 per cent. other cases of congenital blindness. They are as follows :-

1. Congenital hydrophthalmos; the right eye has been iridectomised ; the left burst, and then dirindled whilst an inmate; she died of phthisis.

2. The parents and medical certificate say " born blind," the exact cause doubtful ; the eyeballs are small; the cornea in each is clear, but small. No operation has been performed, as far as information goes.

3. Both optic discs are atrophied; irregular edges suggested a preceding neuritis; there is bare perception of light ; is said to have been born blind.

4. Constant nystagmus; pigment-patches in each fundus; dises atrophied, right bluish white; known to be blind at three months of age.

5 and 6 . A brother and sister, aged at the time of examination respectively $14 \frac{1}{2}$ and 13 . In both, the optic discs were perhaps a little pale, and the vessels were thought to be small, but there was no marked change in the fundus; in the girl there was nystagmus. A communication (at the time of writing) from the father leaves no doubt as to their both having been born blind. The elder one (boy) was early seen by Sir William Bowman, who testified that there "was no light-perception." The parents had four other children, one a boy, preceding the two here mentioned, and three children succeeding, and all possessed good sight; the father and mother were not relatives before marriage. The boy is "far from being bright intellectually"; the little girl is somewhat crippled and dwarfish for her age, is of a bright and happy disposition, but not, I fear, very quick at learning. Hearing in both " is tolerably good." A cousin of the children's father (their grandfather's sister's daughter) had a blind boy and girl. It was the knowledge of this coming to the mother during pregnancy that is assigned as the cause of the blindness in the elder, and the 
thought of the misfortune to the other as the cause of the younger. There is no other blindness in the family, nor have they intermarried; neither father or mother suffered from any nervous disease. Another case at the school would also appear to be congenital. Three of this number were males, and four females. The total number of cases of congenital blininess is 12 , or 16.4 per cent. None under this class are found among the cases reported at the Workshops.

Optic Atrophy. - At the Blind School, 11 owe their affliction to this cause, or 15.2 per cent. ; 9 of this number are females, and 2 males One lost her sight at 21 , and another at 11 ; the others generally when aged 4 or 5 . As far as can be ascertained, the histories resembled those of meningitis: in one, the blindness occurred after whooping-cough (a fit), and another had a blow on the head with a shovel when aged 2.

At the Workshops, there are 8 blind from atrophy of the optic nerve, or 21 per cent. One man, now aged 26 , lost his sight at 7 years of age, during scarlet fever; another, now aged 35 , at 14 was knocked down by an engine, lost his senses, and when consciousness returned, he could not see, and his mind was affected for eighteen months. Another, also, at 15 lost his sight with head-symptoms; he was a file-cutter (saturnine neuritis?). The only female among this series became blind at 19 ; she was under observation with double optic neuritis, passing into atrophy ; cerebral and specific indications were present. The ages at which the others lost their sight were 43,27 , 22 , and 20 . This last was struck on the eye by a piece of grease. He lost consciousness for a time ; there was no vomiting; the sight of the left eye was lost immediately ; of the right, about three weeks later. There was no evidence of injury in the fundus of the left eye ; both optic papillæ were papery white.

The 19 cases in all comprise, out of the 111, a total of 18 per cent. It is worthy of remark that, in three of these instances, there is a history of head-injury.

Cornea. - Affections of the cornea are responsible for 5 cases at the Blind School, or 6.8 per cent. There are 2 males and 3 females. Two of these instances here resulted from interstitial keratitis; one is absolutely deaf. Another case had corneal staphyloma; the globe was painful, and was excised by me before admission into the school; the other eye had corneal fistula, and the little sight then possessed rapidly failed. She died of erysipelas. The other two are stated to have lost their sight whilst " teething;" one, with leucomata, possesses fair sight after iridectomies by Dr. Little, of Manchester, and myself; in the other, the globe (left) is shrunken; an operation had been performed on it in London; the right cornea is cloudly, the pupil closed ; it looks as if irillectomy had been attempted.

At the Workshops, there is one case suflering from the effects of diffuse keratitis. The left cornea is fairly clear, the right still nebulous ; she possesses fair sight.

Iris. - The only case coming under this head deserves longer notice; it is one of irido-ehoroiditis, associated with blanching of the eyelashes. He is employed at the Workshops. In March 1877, he came under my care at the Infirmary. He was then the subject of irido. choroiditis in both eyes. He had first noticed something wrong with his eyes sixteen months before; the left commenced about a fortnight before the right. The eyelashes in both eyelids, on each side, were observed to have become whitened. This alteration in the eyelashes had been first noticed two or three montrs before coming to me. The colour of the hair and eyebrows was brown. I showed the man (then aged 21) to the members of the Sheffield Medico-Chirurgical Society on March 15 th, 1877 , as a "probably unique case." A little later he went to Moorfields, and was under the care of Mr. Jonathan Hutchinson, who has referred to the case in his lectures at the Royal College of Surgeons. Two iridectomies were performed on the right eye. Now (June, 1885) the right globe is shrunken ; in the left eye, the pupil was plugged; the in is bulged forward; there is no perception of light. The eyelashes still remain whitened on both sides; in the upper eyelids, a few darker ones are interspersed.

I will close this report by referring to miscellaneous cases, which I do not otherwise classify.

Coloboma of Iris and Choroid. - The subject had been always defective in sight; at 20 , he was struck by lightning, and lost sight in a few days ; he is now aged 47 . In both eyes there is coloboma below of iris, reaching through the choroid. In the right eye, it embraces the optic disc and affects the sheath. He declined to allow a mydriatic to be used for a thorough examination.

Retinitis Pigmentosa. - A male, aged 43, had nyctalopia as a child. $\mathrm{He}$ could read up to 12 years, holding the book very near. His sight gradually failed, and he has worked in a blind factory for more than twenty years. There was a large quantity of pigment in each fundus, reaching close up to the discs, which are white and waxy-looking.
There are hypermetropia and nystagmus. His father and mother are not relatives; vision of the family is good.

Choroido-retintis. - The subject is a male, aged 42 . His sight commenced to fail at twelve years of age; specific history is denied. In both eyes are atrophic and pigmentary patches; the right eye is less opaque and has perception of light, the left lens is becoming opaque and the vitreous humour cloudy, preventing a perfect view of the fundus; perception of light is defective. He was under observation many years ago.

Hyd̈rophthalmos and Cataract.-A female, aged 38, has been blind since $4 \frac{1}{3}$. The right eye is hydrophthalmic, and has no perception of light. In the left the lens is opaque, the pupil active; there is good perception of light. Her condition, it is possible, might be improved by operation.

The following are among the inmates at the Blind School.

In a boy aged $7:$ "One eye was extracted at 18 months, and the other at $3 \frac{1}{2}$ years, for cancers," so says the medical certificate. The case was not seen by me, and no further information is obtainable.

Another boy, aged $8 \frac{1}{2}$ years, lost his sight at 12 months. There is nystagmus, and examination is very difficult; in each fundus are large pigmentary patches; the discs are atrophied.

Malingering. - This case, a girl, aged $18 \frac{1}{2}$, operated on by $\mathrm{Mr}$. Higgens, for squint (left eye), was sent from a London workhouse, as totally blind. Shortly after admission to the Blind School, sight commenced gradually to recover. When she was examined, hyper. metropia was found, and excellent vision; the left eye was amblyopic. She has since done work at the school, as general servant. I think it likely she feigned blindness at the workhouse, to avoid work, and that she found the education of the blind more irksome than anticipated, and gradually recovered vision.

In conclusion, I must acknowledge the kind services rendered in the preparation of this report by my friend, MIr. J. R. Turner.

\section{TREATMENT OF VARICOCELE BY EXCISION.}

\section{By A. W. MAYO ROBSON, F.R.C.S. Honorary Surgeon to the Leeds General Infirmary}

THE various methods adopted for the cure of varicocele go far to prove that, as yet, no one means is so thoroughly satisfactory as to leave nothing to be desired. Of the various measures I have myself adopted, I have found none to equal, in completeness and safety, the complete excision of the bundle of enlarged veins. After any radical operation for varicocele, there must of necessity be a greatly disturbed circulation in the scrotum, and a liability to hydrocele or slight orchitis, and this I have found occasionally even in subcutaneous ligature of the veins ; but, as will be seen by the following cases, which have occurred in my practice during the last year, orchitis supervened only once, and then in a syphilitic subject, who had had specific orchitis a short time before being treated for varicocele.

The train of nervous symptoms frequently accompanying varicocele is often so severe as to demand treatment; and, when some tangible cause is found, such as a varicose condition of the pampiniform plexus, producing congestion and neuralgia and ultimately atrophy of the testis, it is the surgeon's duty to give relief, especially when it can be done without danger. The operation of excision is performed as follows.

The skin of the scrotum, having been shaved and well washed, is enveloped in a carbolic dressing, which is left on for twelve or twenty. four hours preceding operation.

After the patient has been anæsthetised, and every antiseptic pre. caution adopted, the cord of the affected side is caught between the left finger and thumb over the site of the varicocele; the vas deferens, which is easily felt, is allowed to slip backwards, leaving the enlarged veins within the grasp.

A vertical incision of three-quarters of an inch is now made through skin and fascia, quite down to the veins which immediately bulge through the wound, and are caught between the finger and thumb of the right hand; the finger-nail then serves to break through a film of fascia which separates the veins from the vas deferens. A double No. 2 catgut ligature is passed round the bundle of veins, and the two ligatures thus placed in situ are tied about an inch or more apart, the intermediate varicoeele being completely cut away.

No bleeding occurs, as a rule, and the wound is so small, and falls so well together, that sutures are scarcely required. A small catgut drain may be left in, but this is not absolutely necessary. The wound is covered with carbolised gauze, and over this is placed a good pad of salicylic silk or wool. In some cases, the dressings are not removed for a week, when the wound is completely healed; but, when 